\title{
Association of lupus and a frontal fibrosing alopecia: A case report
}

\author{
Jihane Ziani*, Sara Eloudi, Selma Benkirane, Hanane Baybay, Zakia Douhi and Fatima Zahra Mernissi \\ Department of Dermatology, Hassan II university Hospital, Fez, Morocco
}

\begin{abstract}
There are few reports of the association between Frontal Fibrosing Alopecia (AFF) and lupus. Lupus erythematosus is a recurrent chronic disease accompanied by acute, subacute and chronic lesions. Telogen Effluvium occurs as part of the systemic activity of the disease, and scarring alopecia results from discoid lesions on the scalp. Other types of alopecia, such as alopecia areata, can sometimes be found in lupus. AFF is a typical form of cicatricial alopecia. It can also lead to the development of tiny papules on the frontotemporal region. It occurs mainly in postmenopausal women. The coexistence of AFF and Lupus erythematosus, as observed in our patient, may be indicative of a common pathogenic background.
\end{abstract}

\section{Introduction}

We describe the case of a 46-year-old patient suffering from systemic lupus since the age of 45 , presenting with fibrosing frontal alopecia 3 years before. We discuss the relationship between Frontal Fibrosing Alopecia and lupus erythematosus: an overlap or atypical presentation of scarred alopecia of lupus.

\section{Case report}

46-year-old patient followed for a Frontal Fibrosing Alopecia since 2015 having presented 3 years after a systemic lupus with immunological and rheumatic attack. Clinically the patient reported inflammatory arthralgia with photosensitivity. On a note examined a receding of the frontal edge realizing a cicatricial frontal alopecia with sign of negative traction an almost total depilation of the eyebrows with some fluffy hairs with depilation of the complete members associated color papule. In hair dermoscopy there was an erythematous background, scales and paripillary keratosis, with peripilar pigmentation. A frontal edge biopsy revealed an AFF and the immunological assessment was in favor of lupus (Figure 1).

\section{Discussion}

Both AFF and Lupus are diseases characterized by interface dermatitis. Under such conditions, the basal cells of the epidermis are damaged and the subepithelial inflammatory infiltrate is variable, including cytotoxic T cells and plasmacytoid dendritic cells (pDC). It is assumed that the clinical manifestations of the two diseases are initiated by innate infiltration and activation of pDC. Evidence suggests that activation of $\mathrm{pDC}$ is an early innate key event that triggers a self-reactive cytotoxic T-cell response leading to damage to the basal epidermal layer. In the literature, there are only a few writings concerning this association [1-3]. AFF and LE, have therefore a common history because

Copyright: $\left(C_{2020}\right.$ Ziani J. This is an open-access article distributed under the terms of the Creative Commons Attribution License, which permits unrestricted use, distribution, and reproduction in any medium, provided the original author and source are credited.

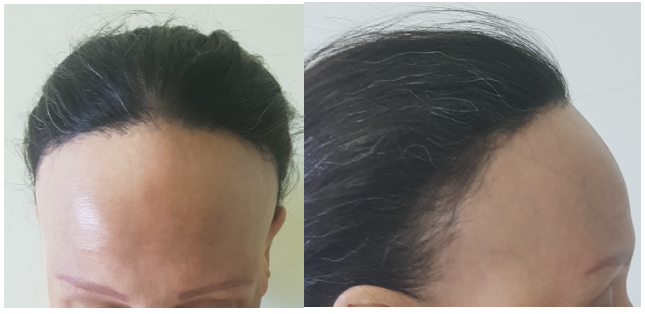

Figure 1. Clinical images of extensive frontal fibrosing alopecia

as it has been well mentioned by other authors, their coexistence is not a coincidence but more a result of a different immune responses due to a genetic predisposition [2]. The histopathological distinction between these two entities can therefore be difficult.

\section{Conclusion}

By extrapolating these data, one could conclude that an innate defense mechanism would then be responsible for triggering the two diseases. Future reports could strengthen this association by helping to assess whether such coexistence is just a coincidence, or new evidence in the case of this association group.

\section{References}

1. Gaffney DC, Sinclair RD, Yong-Gee S (2013) Discoid lupus alopecia complicated by frontal fibrosing alopecia on a background of androge netic alopecia. Br J Dermatol 169: 217-218. [Crossref]

2. del Rei M, Pirmez R, Sodré CT, Tosti A (2016) Coexistence of frontal fibrosing alopecia and dis- coid lupus erythematosus of the scalp in 7 pa- tients: Just a coincidence. $J$ Eur Acad Dermatol Venereol 30:151-153. [Crossref]

3. Khan S, Fenton DA, Stefanato CM (2013) Frontal fibrosing alopecia and lupus overlap in a man: Guilt by association. Int J Trichology 5: 217-219. [Crossref]

*Correspondence to: Jihane Ziani, Department of Dermatology, Hassan II university Hospital, Fez, Morocco, E-mail: dr.zianijihane@gmail.com

Key words: lupus erythematosus, frontal fibrosing alopecia, case report

Received: Mar 02, 2020; Accepted: May 09, 2020; Published: May 16, 2020 